\title{
Epidemiological Profile of Mental Health Program Patients in a Health Unit
}

\author{
Amanda Maués Ramos ${ }^{1}$, Elisa Maria Novaes Barros ${ }^{1}$, Juliana Manoella Monteiro de Oliveira1, \\ Francisco Ipslon Terezo Rosas Junior ${ }^{2}$, Andrew Moraes Monteiro', Vanessa Novaes Barros ${ }^{3 *}$ \\ ${ }^{1}$ Universidade do Estado do Pará (UEPA), Belém, Brazil \\ ${ }^{2}$ Universidade Federal do Pará (UFPA), Belém, Brazil \\ ${ }^{3}$ Neurology/Neuroscience from UNIFESP, Estacio de Castanhal University, Castanhal, Brazil \\ Email: *barros.novaes@hotmail.com
}

How to cite this paper: Ramos, A.M. Barros, E.M.N., de Oliveira, J.M.M., Rosas Junior, F.I.T., Monteiro, A.M. and Barros, V.N. (2020) Epidemiological Profile of Mental Health Program Patients in a Health Unit. Open Journal of Psychiatry, 10, 15-24. https://doi.org/10.4236/ojpsych.2020.101003

Received: November 16, 2019

Accepted: January 7, 2020

Published: January 10, 2020

Copyright (c) 2020 by author(s) and Scientific Research Publishing Inc. This work is licensed under the Creative Commons Attribution International License (CC BY 4.0).

http://creativecommons.org/licenses/by/4.0/

\begin{abstract}
Aim: To verify the epidemiological profile of patients enrolled in the Mental Health Program at a Family Health Unit, as well as the most prevalent disorders, age and comorbidities. Methods: After analyzing the medical records, the following variables were obtained: diagnosis of mental health status, gender, age group, associated comorbidities and medication in use. Results: There was a prevalence of $61.3 \%$ in women and $38.7 \%$ in men; patients aged 30 to 39 years were the most affected (22.6\%); the most common disorders were epilepsy (36\%), depression (14\%), anxiety disorder (8.6\%) and schizophrenia (8.6\%); the most common comorbidities were systemic arterial hypertension (30\%) and insomnia (15\%) and the most commonly used psychotropic drugs were amitriptyline, carbamazepine and phenobarbital (10.2\% each). Conclusion: There was a high prevalence of females, mainly at 30 to 39 years old and the most prevalent diagnoses were epilepsy, depression and anxiety disorder. About medications, antidepressants and anticonvulsants were the most prescribed.
\end{abstract}

\section{Keywords}

Mental Health, Mental Disorders, Comorbidity, Epidemiology, Prevalence, Primary Health Care

\section{Introduction}

Since the 1990s, epidemiology has begun to highlight new demands for care such as mental health, as mental health problems have quietly become the leading cause of disability, morbidity and premature death, in both developed and de- 
veloping countries [1].

Countries all around the world are going through this "epidemiological transition". Diseases such as depressive disorders and cardiovascular disorders are rapidly replacing the prevalence of malnutrition and infectious diseases. However, this process is occurring without the proper awareness of experts in service planning and public health care. Therefore, mental health care is not exempt from the precariousness of humanized treatment [2].

Despite the high prevalence, myths about mental illness and stigmatization persists even among some healthcare professionals who are unaware of the great progress that has been made in recent decades regarding the diagnosis and, especially, treatment of these psychiatric disorders. About the interventions against the stigma of mental illness, one of the major positive impact factors is prior contact by the intervention participant with someone with mental illness [3] [4].

The lack of information about Mental Health actions in Primary Care is evident. In contrast, the patient with mental disorders is guaranteed by law No. 10.216 and has the right to access the best treatment that health system can provide, concerning their needs, and to be treated with humanity and respect with sole interest of benefiting their health, aiming to achieve their recovery through insertion in family, work and community [5].

Since Primary Care is the gateway to brazilian public health system, the insertion of Mental Health actions allows psychic symptoms to be detected and treated early, avoiding unnecessary hospitalizations [6]. In this sense, the Family Health Program (FHP) is the main strategy to enable primary health care, through the proposal of change in the rationality of care, based on a multiprofessional teamwork process in which health surveillance, comprehensiveness of practices, ierarchization, territorialization and enrollment of those registered in the respective program [7].

In addition, current national mental health policy consists with progressive reduction of psychiatric beds and expansion and strengthening of out-of-hospital network, consisting mainly of the Psychosocial Care Centers (CAPS) and Therapeutic Residential Services (SRT). It also includes the importance of mental health actions in primary care [8]. CAPS is a type of community health service that provides daily care to patients with severe and persistent mental disorders, under intensive, semi-intensive and non-intensive treatment, according to severity of clinical condition [9].

In fact, mental health deserves specific attention, given its increasing prevalence in world population. Therefore, considering the scarcity of information about Mental Health actions in primary care, it is necessary to contribute with data about the clinical/epidemiological profile of psychiatric patients treated at the Primary Care of Brazilian Unified Health System (SUS). Thus, the objective of this study is to verify the epidemiological profile of patients enrolled in the Mental Health Program in a FHU, as well as identify the most prevalent disorders, age and comorbidities. 


\section{Methods}

The patients of this research were studied according to the precepts of the Declaration of Helsinki and the Nuremberg Code, respecting the Research Standards Involving Human Beings (Res. 466/12) of the National Health Council, after approval by the direction of the Family Health Unit (USF), in addition to the commitment made by the researchers about the confidentiality of the data used, based on the Term of Commitment to Data usage.

This research is characterized as a cross-sectional, observational, descriptive study, which evaluated the records of the patients enrolled in USF Mental Health Program. The study included patients of both sexes, without age restriction, without distinction about race, educational level, income levels or marital status. These patients should be registered with USF and the Mental Health Program by November 2015.

The study excluded patients whose data in the medical records were not correctly completed and accessible to researchers, and those who were outside the established period for analysis.

The research was developed from the analysis of medical records at the Health Unit, from November to December 2018. This analysis included research on epidemiological variables: diagnosis of mental health status, gender, age group, associated comorbidities and medication in use according to the research protocol model elaborated.

Data was organized according to the mentioned variables, and then was stored in a database created by the researchers themselves using the Excel 2010 software. Subsequently, the variables were analyzed and compared between groups. The statistical study was performed according to the nature of the variables, and descriptive statistical analysis was applied, informing the percentage values of the data analyzed, which were later organized into tables and graphs. For the creation of a database and elaboration of the graphs and tables, the researchers used the programs Excel and Microsoft Word 2010.

\section{Results \& Discussion}

In this study, was observed a higher prevalence among women (Table 1). These data disagree with previous findings of a survey conducted with 97 medical records of a psychiatric unit in the city of Jequié, Bahia, where $54.6 \%$ of patients were actually male [10].

According to Rennó Jr. et al. (2012) [11], from menarche to post-menopause, some women suffer from specific disorders, including premenstrual dysphoric disorder, perinatal and perimenopausal depression, blues and puerperal psychosis, as well as mood and anxiety disorders associated with infertility and aborted pregnancies, and also present higher incidence of anxiety, eating disorders, autoimmune diseases and pain.

In this research, we identified higher prevalence of disorders such as depres- 
sion and generalized anxiety in females (Table 2 and Table 3), that information is in accordance with previous studies [8] [12] that also found a significant difference between genders regarding the diagnosis of mood disorders (more common in women) and psychotic disorders and substance use (higher in men). This can be explained by female tendency to internalize stress in certain situations such as family instability, which leads to disappointment, anxiety, insecurity and affective deficits, culminating in psychological imbalance that results in depression [11].

Women are also frequently exposed to stressors such as violence, abuse and rape since an early age, but not all women who encounter such situations develop disorders. Thus, the interaction between genetic vulnerability, environmental, physiological and psychosocial factors, neurotransmitter and neuroendocrine

Table 1. Gender of patients registered in the USF Mental Health Program in 2018 Ananindeua-PA.

\begin{tabular}{ccc}
\hline Gender & N & $\%$ \\
\hline Female & 38 & 61,3 \\
Male & 24 & 38,7 \\
TOTAL & 62 & 100 \\
\hline
\end{tabular}

Source: Research protocol.

Table 2. Diagnosis of mental disorder of patients enrolled in the USF Mental Health Program in 2018. Ananindeua-PA*.

\begin{tabular}{ccc}
\hline Diagnosis & N & $\%$ \\
\hline Epilepsy & 25 & 36 \\
Depression & 10 & 14 \\
Anxiety disorder & 6 & 8.6 \\
Schizophrenia & 6 & 8.6 \\
Panic Syndrome & 3 & 4.3 \\
Cerebral Palsy & 3 & 4.3 \\
Behavior disorder & 2 & 2.9 \\
Psychosis & 2 & 2.9 \\
Aggressive Disorder & 1 & 1.4 \\
Obsessive-compulsive disorder & 1 & 1.4 \\
Bipolarity & 1 & 1.4 \\
Alzheimer's disease & 1 & 1.4 \\
Psychomotor agitation & 1 & 1.4 \\
Autism & 1 & 1.4 \\
Parkinson's disease & 1 & 1.4 \\
Not specified & 6 & 8.6 \\
TOTAL & 70 & 100
\end{tabular}

Source: research protocol. ${ }^{\star}$ Each patient may have more than one diagnosis. 
Table 3. Relationship between diagnosis and gender of patients enrolled in the USF Mental Health Program. Ananindeua-PA*.

\begin{tabular}{ccc}
\hline Diagnosis & Female & Male \\
\hline Epilepsy & 12 & 13 \\
Depression & 9 & 1 \\
Anxiety disorder & 4 & 2 \\
Schizophrenia & 3 & 3 \\
Psychosis & 2 & 0 \\
Cerebral Palsy & 1 & 2 \\
Panic Syndrome & 3 & 0 \\
Aggressive Disorder & 0 & 1 \\
Obsessive-compulsive disorder & 0 & 1 \\
Bipolarity & 0 & 1 \\
Alzheimer's disease & 1 & 0 \\
Psychomotor agitation & 0 & 1 \\
Behavior disorder & 2 & 0 \\
Autism & 1 & 0 \\
Parkinson's disease & 3 & 0 \\
Not specified & 1 & 3 \\
TOTAL & 2 & 0 \\
\hline
\end{tabular}

Source: research protocol. *Each patient may have more than one diagnosis.

functioning plays an important role in their pathogenesis [11].

The association between psychiatric disorders and metabolic disorders has long been described. Individuals with mental disorders constitute a group of high morbidity and mortality. The standardized mortality rate of individuals with schizophrenia is 1.5 to 4 times the general population, and deaths from natural causes account for almost two thirds of this excess, with a significant increase in mortality indicators related to diabetes and cerebrovascular disease. Depression confers a 1.5 to 2.5 fold relative risk for morbidity and mortality from cardiac causes. It is postulated that the serotonergic system is involved in the association between metabolic syndrome and depression. Decreased serotonergic function is associated with increased carbohydrate intake, bulimic episodes and obesity [13].

To relieve such depression as well as symptoms of other mental disorders, it is common for patients to adopt a high calorie diet (with excessive carbohydrates and fats and low in fiber) due to its anxiolytic effect caused by reduction of hormone levels [14]. However, such practice often leads to excessive weight gain, which in turn culminates in other clinical complications such as systemic arterial hypertension, one of the most prevalent among these patients [15], as evidenced on Figure 1. In addition, many psychiatric drugs have important side effects re- 
lated to metabolic syndrome, such as weight gain, changes in glucose metabolism and dyslipidemia [11].

The existence of an association between severe mental disorders and high blood pressure is questionable, particularly in patients with schizophrenia. However, the presence of depressive symptoms may be a predisposing factor for the onset of hypertension. Two prospective studies specifically assessed this topic and found increased risk of hypertension in patients with high scores of depressive symptoms. The first, with follow-up of 7 to 16 years, concluded that high levels of anxiety or depression are associated with higher incidence of hypertension in white individuals aged 45 to 64 years or in black individuals aged 25 to 64 years [16]. The second, a follow up of young men for five years, also showed that high scores of depressive symptoms are associated with a higher incidence of hypertension [17].

Regarding the age group (Figure 2), most corresponded to adults, the longest phase of life, in which peak of personal achievements such as marriage, child

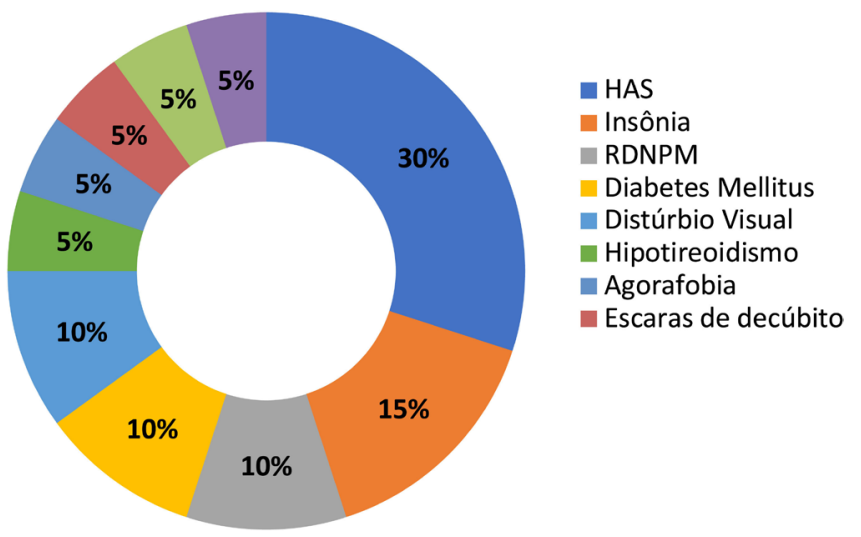

Source: Research protocol.

Figure 1. Associated comorbidities presented by patients registered in the USF Mental Health Program. Ananindeua-PA.

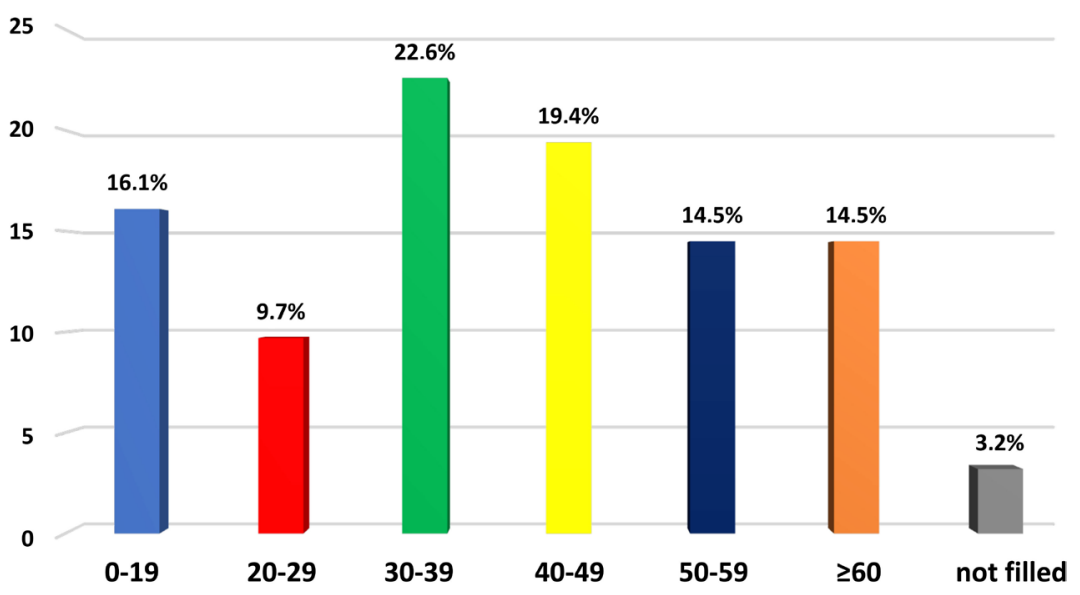

Source: Research protocol.

Figure 2. Age range of patients enrolled in the USF Mental Health Program in 2018. Ananindeua-PA. 
Table 4. Psychoactive medications used by patients enrolled in the USF Mental Health Program in 2018. Ananindeua-PA*.

\begin{tabular}{|c|c|c|}
\hline Medication & $\mathbf{N}$ & $\%$ \\
\hline Amitriptyline & 12 & 10.2 \\
\hline Carbamazepine & 12 & 10.2 \\
\hline Phenobarbital & 12 & 10.2 \\
\hline Risperidone & 9 & 7.7 \\
\hline Haloperidol & 9 & 7.7 \\
\hline Diazepam & 8 & 6.85 \\
\hline Biperiden & 8 & 6.85 \\
\hline Levomepromazine & 6 & 5.1 \\
\hline Clonazepam & 5 & 4.3 \\
\hline Phenytoin & 5 & 4.3 \\
\hline Promethazine & 5 & 4.3 \\
\hline Paroxetine & 4 & 3.4 \\
\hline Chlorpromazine & 4 & 3.4 \\
\hline Valproic acid & 4 & 3.4 \\
\hline Pipothiazine Palmitate & 2 & 1.71 \\
\hline Sertraline & 2 & 1.71 \\
\hline Topiramate & 1 & 0.85 \\
\hline Gabapentin & 1 & 0.85 \\
\hline Memantine Hydrochloride & 1 & 0.85 \\
\hline Oxcarbazepine & 1 & 0.85 \\
\hline Clobazam & 1 & 0.85 \\
\hline Escitalopram & 1 & 0.85 \\
\hline Periciazine & 1 & 0.85 \\
\hline Thioridazine & 1 & 0.85 \\
\hline Donepezil Chloridate & 1 & 0.85 \\
\hline Discontinued Treatment & 1 & 0.85 \\
\hline TOTAL & 117 & 100 \\
\hline
\end{tabular}

Source: research protocol. ${ }^{*}$ Each patient may use more than one medication.

Table 5. Adherence to psychoactive drug treatment by patients registered with the USF Mental Health Program. Ananindeua-PA.

\begin{tabular}{ccc}
\hline Adherence to treatment & N & $\%$ \\
\hline Yes & 61 & 98.4 \\
No & 1 & 1.6 \\
TOTAL & 62 & 100 \\
\hline
\end{tabular}

Source: research protocol. 
rearing and work activities should occur. However, the presence of mental disorders in this age group often negatively influences the way of life, as it disrupts person's productivity due to their chronicity [10] [18].

Some factors related to socioeconomic conditions, such as unemployment, low education, marital status, gender, poor housing conditions, informal work, and non-access to consumer goods, were identified as possible determinants to high levels of mental disorders in analyzed studies [19].

Mental health assumes an ethical-political commitment that seeks the care of people in psychological distress through respect for their uniqueness and social reintegration. Noteworthy, as part of the therapeutic actions in the psychosocial context is drug treatment, which aims to reduce the harmful symptoms of psychiatric disorders, with the purpose of better adaptation to reality [20].

Therefore, regarding treatment, use of psychotropic drugs, such as amitriptyline and carbamazepine, was quite frequent (Table 4), which agrees with previous studies [8] [12] [15] that noted that the majority of patients who were regulars of CAPS, used some psychopharmaceutical. This high drug based treatment may be justified by its use in controlling and decreasing the symptoms of mental disorders, especially in those manifested by psychosis and depressed mood.

Good adherence to treatment (Table 5) including psychotropic drugs may be related to significant improvement of individuals who use them. According to Xavier et al. (2014) [20], usage of psychotropic drugs brought, in a certain way, a statement of normality for users. It was observed that, sometimes, psychotropic drugs are considered an integral part of users' lives, without them they would not be able to perform their daily functions. In some moments they showed to be aware of the damage of not using, as well as revealed their expectations for cure. Therefore, therapeutic interventions should not be restricted to drug prescription.

Another important data, was the identification of an important deficit of information in medical records and previous studies also point out that same difficulty [12]. Proper and organized medical records is essential to support the direction in production of care, as it allows the planning of actions, serving as a legal instrument for the entire team of health care.

\section{Conclusions}

The profile of mental health service users is characterized by females, mainly at 30 to 39 years old and the most prevalent diagnoses were epilepsy, depression and anxiety disorder. About medications, antidepressants and anticonvulsants were the most prescribed.

It is suggested that other studies of this nature should be carried out, in order to enable the recognition of the context of mental health care of the municipalities, since the characterization of this demand enables the recognition of possible existing barriers to the work process of the Unified Health System (SUS) services. 


\section{Conflicts of Interest}

The authors declare no conflicts of interest regarding the publication of this paper.

\section{References}

[1] Andrade, L. (1999) Epidemologia psiquiátrica. Novos desafios para o século XXI. Revista USP, No. 43, 84. https://doi.org/10.11606/issn.2316-9036.v0i43p84-89

[2] Murray, C. and Lopez, A. (1996) The Global Burden of Disease. Harvard School of Public Health on Behalf of the World Health Organization and the World Bank, Cambridge, MA.

[3] Penn, D., Chamberlin, C. and Mueser, K. (2003) The Effects of a Documentary Film About Schizophrenia on Psychiatric Stigma. Schizophrenia Bulletin, 29, 383-391. https://doi.org/10.1093/oxfordjournals.schbul.a007012

[4] Grabriela, C. (2006) Crenças e atitudes estigma em relação a portadores de esquizofrenia em adolescentes estudantes da série intermediaria do ensino médio: Avaliação e intervenção [Mestrado]. Universidade Federal de São Paulo (UNIFESP), São Paulo.

[5] Brasil, Lei No. 10.216 (2001) Dispõe sobre a proteção e os direitos das pessoas portadoras de transtornos mentais e redireciona o modelo assistencial em saúde mental. Diário Oficial da União. http://www.planalto.gov.br/ccivil_03/leis/leis_2001/110216.htm

[6] Modesto, T.N. and Santos, D.N. (2007) Saúde mental na atenção básica. Revista Baiana de Saúde Pública, 31, 19-24.

[7] Vecchia, M. (2006) A saúde mental no Programa de Saúde da Família: estudo sobre práticas e significações de uma equipe [Mestrado]. Universidade Estadual Paulista (UNESP), São Paulo.

[8] Mangualde, A.A.S., Botelho, C.C., Soares, M.R., Costa, J.F., Junqueira, A.C. and Vidal, C.E. (2013) Perfil epidemiológico dos pacientes atendidos em um Centro de Atenção Psicossocial. Mental, 10, 235-248.

[9] Brasil (2004) Relatório Final da XII Conferência Nacional de Saúde. Conselho Nacional de Saúde.

http://conselho.saude.gov.br/biblioteca/Relatorios/relatorio_12.pdf

[10] Cruz, D.P., Sena, E.L.S., Moreira, R.M., Teixeira, J.R.B., Lira, S.P., Santana, L., Ferraz dos Anjos, K. and Cruz Santos, V. (2014) Perfil clínico y epidemiológico de pacientes atendidos en ambulatorio psiquiátrico. Revista Cubana de Enfermería, 30.

[11] Rennó, J.R., Demarque, R., Lobo, H.R., Cavalsan, J.P. and Silva, A.D. (2012) Saúde Mental da Mulher: Transtornos psiquiátricos relacionados ao ciclo reprodutivo. $R e-$ vista debates em psiquiatria, 2, 6-11.

[12] Pereira, M.O., Souza, J.M., Costa, A.M., Vargas, D., Oliveira, M.A.F. and Moura, W.N. (2012) Perfil dos usuários de serviços de Saúde Mental do município de Lorena-São Paulo. Acta Paulista de Enfermagem, 25, 48-54. https://doi.org/10.1590/S0103-21002012000100009

[13] Teixeira, P.J. and Rocha, F.L. (2007) Associação entre síndrome metabólica e transtornos mentais. Archives of Clinical Psychiatry, 34, 28-38. https://doi.org/10.1590/S0101-60832007000100005

[14] Gomes, F.A. (1996) Comorbidades clínicas em psiquiatria. Atheneu, São Paulo.

[15] Sordi, D., Petelincar, L., Bigatto, K.R., Santos, S.G. and Machado, A.L. (2015) Com- 
orbidades em usuários de um serviço de saúde mental. Revista Portuguesa de Enfermagem de Saúde Mental, No. 2, 89-94.

[16] Jonas, B.S., Franks, P. and Ingram, D.D. (1997) Are Symptoms of Anxiety and Depression Risk Factors for Hypertension? Longitudinal Evidence from the National Health and Nutrition Examination Survey I Epidemiologic Follow-up Study. Archives of Family Medicine, 6, 43-49. https://doi.org/10.1001/archfami.6.1.43

[17] Davidson, K., Jonas, B.S., Dixon, K.E. and Markovitz, J.H. (2000) Do Depression Symptoms Predict Early Hypertension Incidence in Young Adults in the CARDIA Study? Archives of Internal Medicine, 160, 1495-500.

https://doi.org/10.1001/archinte.160.10.1495

[18] da Silva, T.L., Maftum, M.A., Kalinke, L.P., de Freitas Mathias, T.A., Ferreira, A.C. and Capistrano, F.C. (2015) Perfil sociodemográfico e clínico dos pacientes em tratamento na unidade psiquiátrica de um hospital geral. Cogitare Enfermagem, 20, page. https://doi.org/10.5380/ce.v20i1.36414

[19] Santos, É.G. and Siqueira, M.M. (2010) Prevalência dos transtornos mentais na população adulta brasileira: Uma revisão sistemática de 1997 a 2009. Jornal Brasileiro de Psiquiatria, 59, 238-246. https://doi.org/10.1590/S0047-20852010000300011

[20] da Silva Xavier, M., Terra, M.G., da Silva, C.T., de Souza Mostardeiro, S.C., da Silva, A.A. and de Freitas, F.F. (2014) O significado da utilização de psicofármacos para indivíduos com transtorno mental em acompanhamento ambulatorial. Escola Anna Nery Revista de Enfermagem, 18, 323-329. 